\title{
Meta-analysis of metabolic syndrome and its individual components with risk of atrial fibrillation in different populations
}

Ying Zheng ${ }^{1,2 \dagger}$, Zengshuo Xie ${ }^{2,3 \dagger}$, Jiayong $\mathrm{Li}^{2,3}$, Chen Chen ${ }^{2,3}$, Wenting Cai ${ }^{2,3}$, Yugang Dong ${ }^{2,3,4}$, Ruicong Xue ${ }^{2,3,4}$ and Chen Liu $2,3,4^{*}$ (B)

\begin{abstract}
Background: Recent studies have reported the effects of metabolic syndrome (MetS) and its components on atrial fibrillation (AF), but the results remain controversial. Therefore, we performed a meta-analysis to evaluate the relationship between MetS and AF risk.

Methods: Studies were searched from the Cochrane library, PubMed, and Embase databases through May 2020. Adjusted hazard ratios (HRs) and its corresponding 95\% confidence intervals (Cls) were extracted and then pooled by using a random effects model.

Results: A total of 6 observational cohort studies were finally included. In the pooled analysis, MetS was associated with an increased risk of AF (HR 1.57; 95\% Cl 1.40-1.77; $P<0.01)$. And the components of MetS including abdominal obesity (HR 1.37; 95\% Cl 1.36-1.38; $P<0.01$ ), elevated blood pressure (HR 1.56; 95\% Cl 1.46-1.66; $P<0.01$ ), elevated fasting glucose (HR 1.18; 95\% Cl 1.15-1.21; $P<0.01)$ and low high density cholesterol (HDL) (HR 1.18; 95\% Cl 1.06-1.32; $P<0.01$ ) was also associated with an increased risk of $A F$, while high triglyceride ( $\mathrm{HR} 0.99 ; 95 \% \mathrm{Cl} 0.87-1.11, P=0.82$ ) was not.

Conclusions: Our present meta-analysis suggested that MetS, as well as its components including abdominal obesity, elevated blood pressure, elevated fasting glucose and low HDL cholesterol were associated with an increase in the risk of $\mathrm{AF}$.
\end{abstract}

Keywords: Metabolic syndrome, Atrial fibrillation, Observational cohort study, Risk factor

\section{Background}

Atrial fibrillation (AF) is the most common arrhythmia with an estimated 33.3 million affected people in the world in 2015 [1]. By 2050, the prevalence of AF in people over the age of 60 is estimated to increase from 3.9 million to 9 million [2]. AF is associated with a fivefold risk

\footnotetext{
*Correspondence: liuch75@mail.sysu.edu.cn

${ }^{\dagger}$ Ying Zheng and Zengshuo Xie contributed equally to this work and should be considered co-first authors

${ }^{2}$ Department of Cardiology, The First Affiliated Hospital of Sun Yat-Sen University, Guangzhou 510080, China

Full list of author information is available at the end of the article
}

for stroke and causes $15 \%$ of all strokes [3]. In addition, $\mathrm{AF}$ is an independent risk factor for death, with a 1.5-fold risk for men and 1.9-fold risk for women for mortality after adjustment for known risk factors [4]. Therefore, it is important to investigate the etiology and influencing factors of AF.

Metabolic syndrome (MetS) represents a series of cardiovascular and metabolic disorders, defined as a cluster of central obesity, hypertension, dyslipidemia, and glucose intolerance [5]. MetS worsens vascular function and causes subclinical damage in multiple organs, which is a more serious single risk factor than traditional 
one [6]. Prior studies have found that the prevalence of $\mathrm{AF}$ increases in parallel with the frequency of MetS [7]. Epidemiological studies conducted in Asian population samples [8-11] and Western population samples [12, 13] showed that patients with MetS are more likely to have AF than patients without MetS. In addition, the increase in the number of components of the MetS is related to the occurrence of AF [14]. Despite the relatively large amount of evidence, there are differences in the estimates of the studies above, so we cannot assess the extent to which the MetS and its components affect AF [8-13]. Therefore, we conducted a systematic review and metaanalysis to observe the impact of MetS or its individual components on the incidence of AF.

\section{Methods}

This meta-analysis was performed by following the Meta-Analysis of Observational Studies in Epidemiology (MOOSE) [15]. Meta-analysis of available articles does not require ethics approval.

\section{Definitions of MetS}

The definitions of MetS adopted by the included studies in this article are not exactly the same, including National Cholesterol Education Program-Third Adult Treatment Panel (NCEP-ATPIII) [16], International Diabetes Federation [17] and American Heart Association and National Heart, Lung, and Blood Institute (AHA/NHLBI) [18]; and the study Nyström-2015 adopted other definition standards (see Additioanl file 1: Table 1).

\section{Literature search}

We searched the original studies from the Cochrane library, PubMed, and Embase databases through May 2020. We combine the key words about 'atrial fibrillation' with the key words about 'metabolic syndrome' to search the relevant studies (see Additioanl file 1: Table 2). In addition, we also reviewed the references of the retrieved studies for further research. There was no language limitation used in the process.

\section{Eligibility criteria}

Observational cohorts were adopted if they met all of the following criteria: (1) evaluating the effects of MetS and/ or its components (abdominal obesity, elevated blood pressure, elevated fasting glucose, low high density cholesterol (HDL) and high triglyceride) on the risk of AF; (2) adjusted hazard ratios (HRs) and corresponding 95\% confidence intervals (CIs) were regarded as the effect values. The exclusion criteria were as follows: (1) outcomes of the study were other AF-related diseases (e.g., AF recurrence, postoperative AF or atrial flutter); (2) certain publication types with no relevant data (e.g., reviews, letters, case reports, comments).

\section{Data extraction}

The following data of all included articles was retrieved by Ying Zheng Ph.D. and Zengshuo Xie: author(s) name, publication year, country of original study, design of study, sample characteristics of study population (size, age range and gender composition), diagnostic criteria of MetS, outcome, and adjusted HRs with 95\% CIs. If there were more than one HRs available in one study, the most fully adjusted one was used. Besides, in the cohort studies, we preferred to extract the risk estimates for the longest follow-up time. In addition, if one cohort was more than once published, we extracted the most recent one instead.

\section{Quality assessment}

For the quality assessment, the selected cohort studies were evaluated by Newcastle-Ottawa scale (NOS). The quality of the studies was rated with a score from 0 to 9 , representing the risk of bias from high to low [19]. Studies with a summary score above the median were considered to have low risk of bias.

\section{Statistical analysis}

The primary results of this meta-analysis were focused on the prevalence of AF in people with MetS versus those without. In addition, the effects of individual components of MetS were also evaluated. Then, the effects were weighted against that calculated for MetS per se using the same datasets. I2 test was used to assessed Heterogeneity among the included studies (I $2 \geq 25 \%, \mathrm{I} 2 \geq 50 \%$, and $\mathrm{I} 2 \geq 75 \%$ were respectively defined as low, moderate, and high heterogeneity) [20]. The risk estimates and 95\%CIs were accordingly transformed to natural logarithm (log HR) and standard error (SE). A random effects model was selected to calculate the summary results. It was reported that this model is more conservative than the fixed-effects models, and could provide better estimates with wider confidence intervals [21]. According to the Cochrane book, if $<10$ studies are included, neither funnel plots nor statistical tests ([i.e., Begg test and Egger test) can be used meaningfully to test for publication bias.

All statistical analysis processes were executed by statistical software Revman Manager 5.3 (Nordic Cochrane Center; http://ims.cochrane.org/revman).

\section{Results \\ Study selection}

Figure 1 shows the literature search process. Among 335 articles identified from the databases, we included 


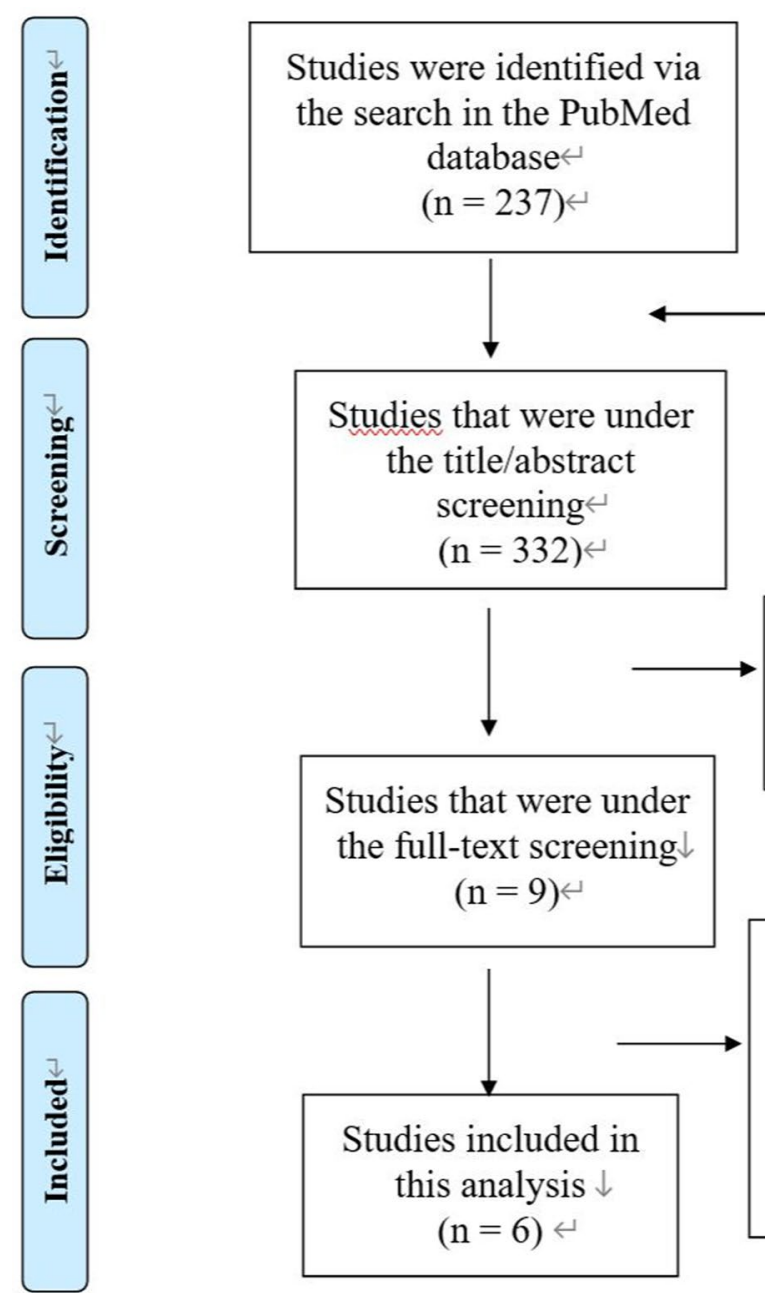

Additional records identified through other sources $(\mathrm{n}=95)$
2 studies were excluded:

1. No analysis of the relative risk or odds ratio of metabolic syndrome or its components to atrial fibrillation $(\mathrm{n}=2)$

2. Not a cohort study $(n=1)$.

Fig. 1 Study search diagram

6 studies for analysis, including 4 prospective cohorts $[8,10,12,13]$ and 2 retrospective cohorts $[9,11]$, which described their results with HRs.

Table 1 summarizes the patients characteristics of the included studies. A total of $30,810,460$ patients were analyzed, including 7,544,393 or 7,545,221 cases of MetS (with different definitions). The population included in the studies included Korean [9-11], Japanese [8], American [12] and Stockholmer [13]. Among them, one study [12] used the AHA/NHLBI criteria for the diagnosis of MetS and another one [10] used the International Diabetes Federation criteria. Two studies $[9,11]$ diagnosed the MetS according to the NCEPATPIII criteria. One study [8] conducted in Japan calculated the effects of MetS confirmed to NCEPATPIII and AHA/NHLBI criteria respectively. The last one study [13] used other definition.
The NOS scores of the included literatures are all greater than 6 and the qualities of them are acceptable.

\section{MetS with AF risk}

There were 4 studies [9-12] included in this part. The other 2 were excluded because Watanabe-2008 [8] defined obesity with Body Mass Index (BMI), instead of waist circumference (WC); Nyström-2015 [13] used normal weight, no MetS as the reference in statistics. Our meta-analysis showed that patients with MetS were at an increased risk of AF (RR 1.57; 95\% CI 1.40-1.77; Fig. 2) as compared with those without MetS, with significant heterogeneity $(\mathrm{I} 2=97 \%)$.

\section{Association of individual components of MetS with AF risk} Abdominal obesity The risk of AF was elevated in patients with abdominal obesity as compared to those without 
Table 1 Summary of included studies in this meta-analysis

\begin{tabular}{|c|c|c|c|c|c|c|c|}
\hline Studies & Study design & Total case (n) & Population & MetS rate & MetS definition & $\begin{array}{l}\text { Follow-up, } \\
\text { (years) }\end{array}$ & AF rate \\
\hline Choe-2019 & $\begin{array}{l}\text { Retrospective cohort } \\
\text { study }\end{array}$ & $22,886,663$ & $\begin{array}{l}\text { Korean } \\
\text { (aged > } 40 \text { years) } \\
\text { from the Korean } \\
\text { National Health } \\
\text { Insurance Service } \\
\text { from } 2008 \text { to } 2013\end{array}$ & $27.4 \%$ & NCEP-ATPIII & 5.4 & $0.98 \%$ \\
\hline Kwon-2019 & $\begin{array}{l}\text { Retrospective cohort } \\
\text { study }\end{array}$ & $7,830,602$ & $\begin{array}{l}\text { Korean (aged } \\
30-69 \text { years) } \\
\text { from the Korean } \\
\text { National Health } \\
\text { Insurance Service } \\
\text { from } 2009 \text { to } 2016\end{array}$ & $15.9 \%$ & NCEP-ATPIII & 7.3 & $0.26 \%$ \\
\hline Kim-2018 & $\begin{array}{l}\text { Prospective cohort } \\
\text { study }\end{array}$ & 21,981 & $\begin{array}{l}\text { Korean men from a } \\
\text { health screening } \\
\text { program from } 2003 \\
\text { to } 2008\end{array}$ & $11.5 \%$ & $\begin{array}{l}\text { International Diabe- } \\
\text { tes Federation }\end{array}$ & 8.7 & $0.8 \%$ \\
\hline Chamberlain-2010 & $\begin{array}{l}\text { Prospective cohort } \\
\text { study }\end{array}$ & 15,094 & $\begin{array}{l}\text { American (aged } \\
\text { 45-64 years) from } \\
\text { Atherosclerosis } \\
\text { Risk in Communi- } \\
\text { ties study from } \\
\text { 1987-1989 }\end{array}$ & $41.1 \%$ & AHA/NHLBI & 15.4 & $8.2 \%$ \\
\hline Nyström-2015 & $\begin{array}{l}\text { Prospective cohort } \\
\text { study }\end{array}$ & 4,021 & $\begin{array}{l}\text { Stockholmer (aged } \\
60 \text { years) from a } \\
\text { health-screening } \\
\text { study in Stockholm } \\
\text { from August } 1997 \\
\text { to March } 1999\end{array}$ & $27.6 \%$ & $\begin{array}{l}\text { Other definition } \\
\text { standards }\end{array}$ & 13.6 & $7.1 \%$ \\
\hline Watanabe-2008 & $\begin{array}{l}\text { Prospective cohort } \\
\text { study }\end{array}$ & 28,449 & $\begin{array}{l}\text { Japanese } \\
\text { (aged } \geq 20 \text { years) } \\
\text { from an annual } \\
\text { health examina- } \\
\text { tion at the Niigata } \\
\text { Association for } \\
\text { Comprehensive } \\
\text { Health Promotion } \\
\text { and Research }\end{array}$ & $\begin{array}{l}13 \% \text { for NCEP-ATPIII; } \\
16 \% \text { for AHA/ } \\
\text { NHLBI }\end{array}$ & $\begin{array}{l}\text { NCEP-ATPIII or AHA/ } \\
\text { NHLBI }\end{array}$ & 4.5 & $0.9 \%$ \\
\hline
\end{tabular}

Metabolic syndrome $=$ MetS; National Cholesterol Education Program-Third Adult Treatment Panel = NCEP-ATPIIl; American Heart Association and National Heart, Lung, and Blood Institute $=\mathrm{AHA} / \mathrm{NHLBI}$

\begin{tabular}{|c|c|c|c|c|c|c|c|c|}
\hline \multirow{2}{*}{ Study or Subgroup } & log[Hazard Ratio] & SE & Weight & $\begin{array}{c}\text { Hazard Ratio } \\
\text { IV. Random, } 95 \% \mathrm{Cl}\end{array}$ & \multicolumn{4}{|c|}{$\begin{array}{c}\text { Hazard Ratio } \\
\text { IV. Random, } 95 \% \mathrm{Cl}\end{array}$} \\
\hline & 0.513 & 0.058 & $21.7 \%$ & $1.67[1.49,1.87]$ & & & - & \\
\hline Choe-2019 & 0.319 & 0.004 & $27.0 \%$ & $1.38[1.37,1.39]$ & & & $\mathbf{\square}$ & \\
\hline Kim-2018 & 0.451 & 0.021 & $26.2 \%$ & $1.57[1.51,1.64]$ & & & - & \\
\hline Kwon-2019 & 0.543 & 0.031 & $25.2 \%$ & $1.72[1.62,1.83]$ & & & $\square$ & \\
\hline Total $(95 \% \mathrm{Cl})$ & & & $100.0 \%$ & $1.57[1.40,1.77]$ & & & $\diamond$ & \\
\hline $\begin{array}{l}\text { Heterogeneity: } \mathrm{Tau}^{2}= \\
\text { Test for overall effect: }\end{array}$ & $\begin{array}{l}0.01 ; \mathrm{Chi}^{2}=97.64, \mathrm{df} \\
Z=7.44(P<0.00001\end{array}$ & $=3(P$ & $<0.00001$ & $; 1^{2}=97 \%$ & 0.01 & 0.1 & 10 & 100 \\
\hline
\end{tabular}

abdominal obesity (RR 1.37; 95\% CI 1.36-1.38, Fig. 3), with little heterogeneity (I2 $=0 \%)$. It is worth noting that after sorting by BMI, the risk of AF according to abdominal obesity was analyzed in various populations (normal; obese; overweight), and the results showed that abdominal obesity could not be proved to have a higher risk.

Elevated blood pressure Our study showed that the risk of $\mathrm{AF}$ was elevated in patients with elevated blood 
pressure compare with those without elevated blood pressure (RR 1.56; 95\% CI 1.46-1.66, Fig. 4), with moderate heterogeneity $(\mathrm{I} 2=71 \%)$.

Elevated fasting glucose The risk of AF was elevated in patients with elevated fasting glucose compare with those without elevated fasting glucose (RR 1.18; 95\% CI 1.151.21 , Fig. 5), with low heterogeneity ( $12=25 \%)$.
Low HDL cholesterol The risk of AF was elevated in patients with low HDL cholesterol compare with those without low HDL cholesterol (RR 1.18; 95\% CI 1.061.32, Fig. 6), with significant heterogeneity ( $\mathrm{I} 2=87 \%)$.

High triglyceride The risk of AF was not elevated in patients with high triglyceride compare with those

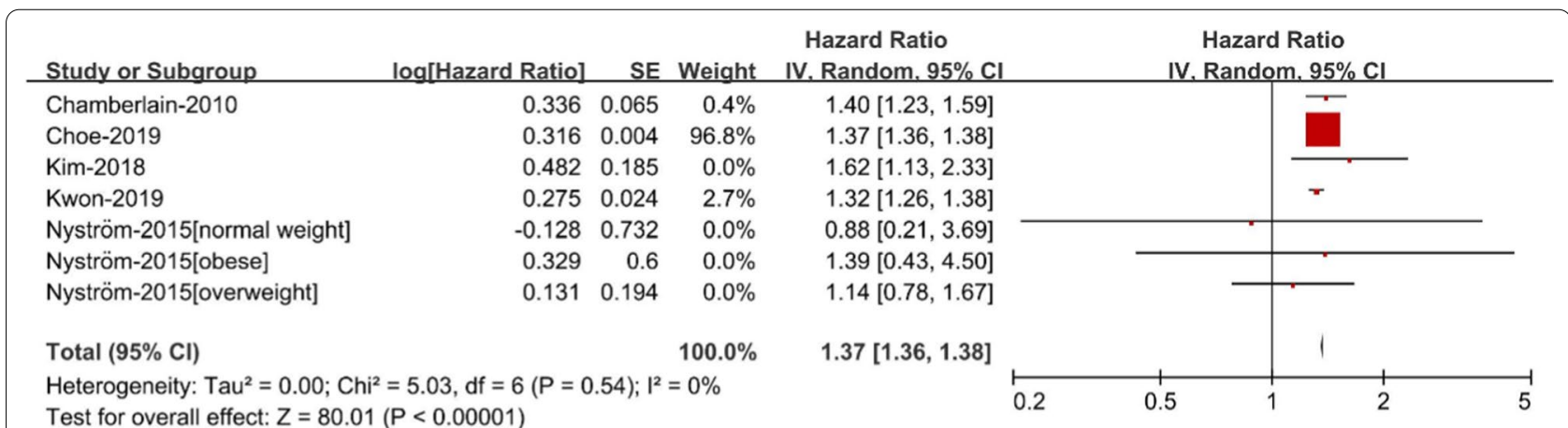

Fig. 3 Risk of atrial fibrillation according to individual components of metabolic syndrome-Abdominal obesity

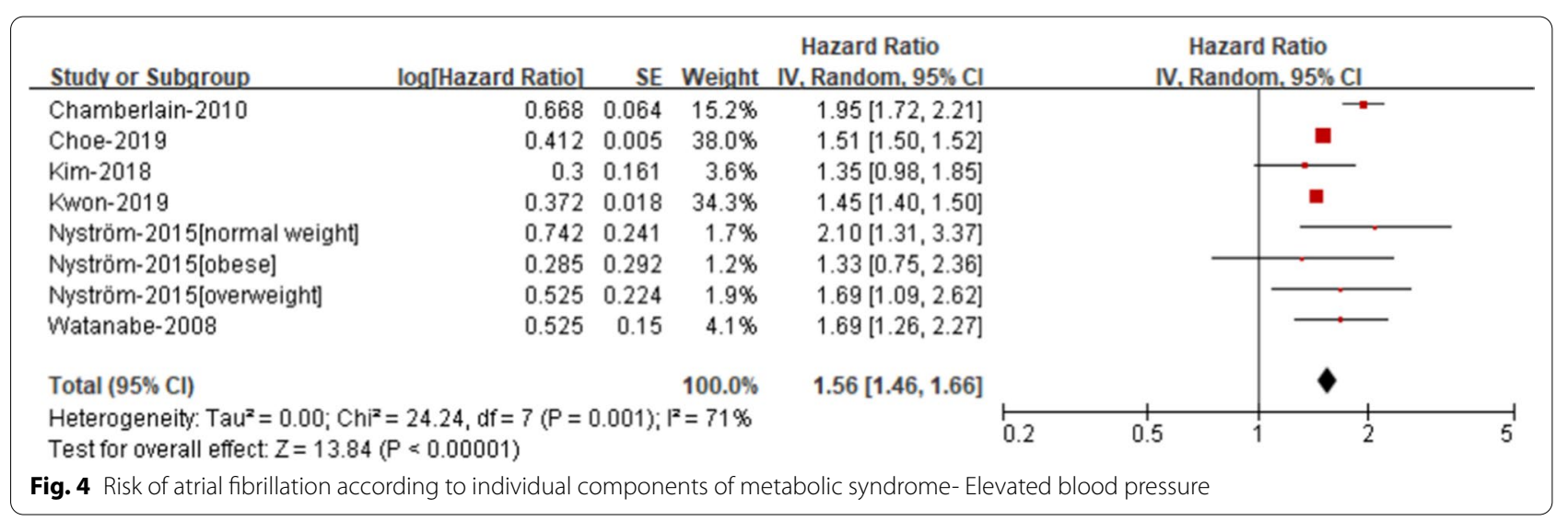

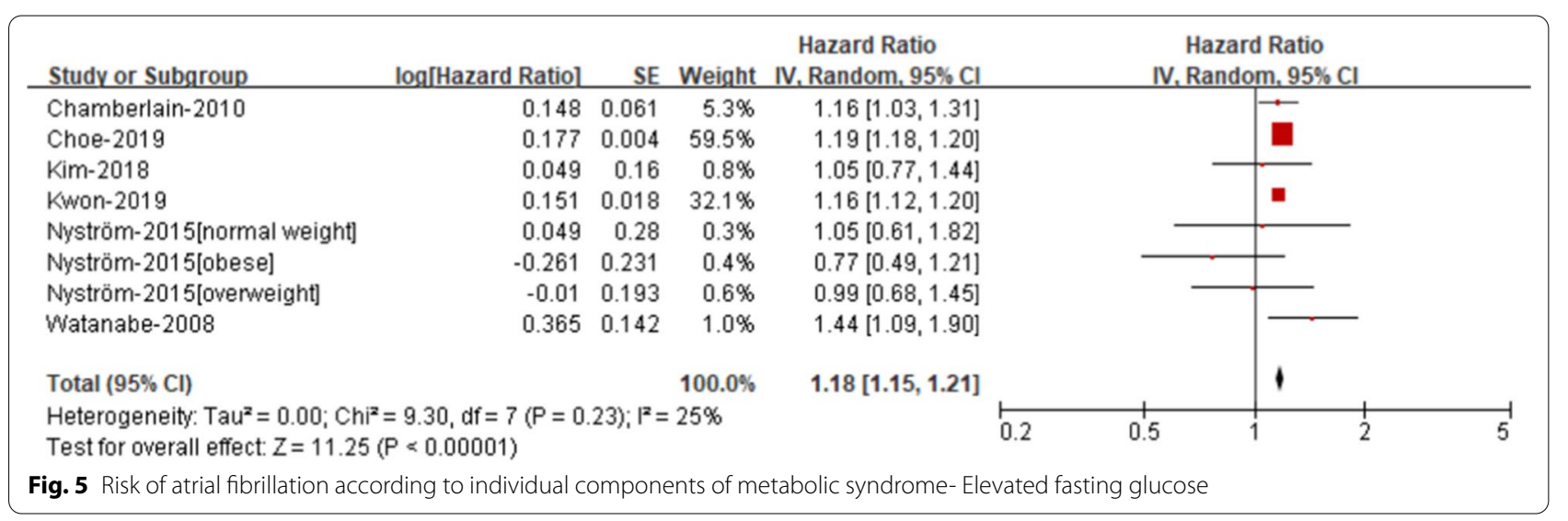




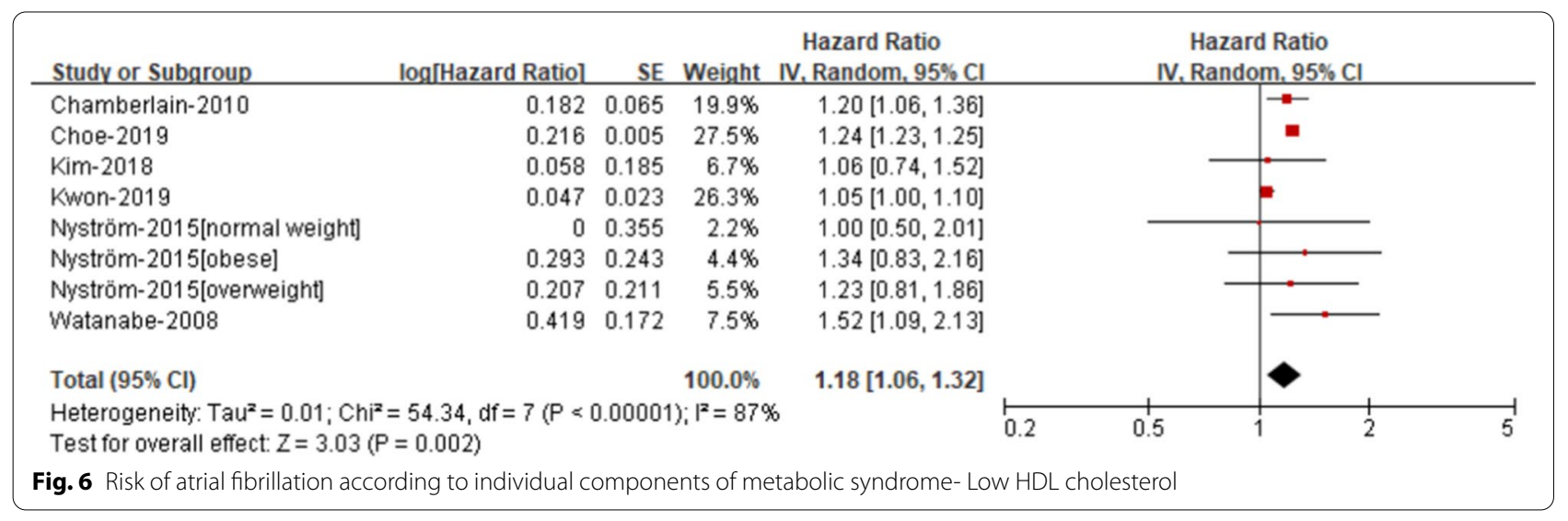

without high triglyceride (RR $0.99 ; 95 \%$ CI $0.87-1.11$, Fig. 7), with significant heterogeneity (I2=91\%).

\section{Publication bias and sensitivity analysis}

Since 6 studies evaluated the effects of MetS and its components on risks of AF, we did not examine the publication bias in this meta-analysis. In spite of this, the results were not changed in the sensitivity analysis as performed by removing the included studies one by one.

\section{Discussion}

To our knowledge, this is the first meta-analysis of published studies from different regions to examine the relationship between MetS and AF risk. Our metaanalysis showed that patients with MetS were at an increased risk of AF as compared with those without MetS. For the components of MetS, abdominal obesity, elevated blood pressure, elevated fasting glucose and low HDL cholesterol were associated with an increase in the risk of AF.

\section{Comparison with other studies}

There is no meta-analysis on the relationship between the risk of AF and MetS as well as its components. Many prior studies reported individual components of MetS as independent predictors of the risk of AF instead of evaluating all the MetS components [22-24]. Our result that MetS and its components can increase the risk of AF is roughly consistent with the results of previous clinical research. It is found that MetS is highly associated with paroxysmal AF and/or atrial flutter in patients without structural heart diseases [25]. Another study showed that in non-diabetic patients with non-essential hypertension, MetS is directly related to and independent of the prevalence of AF [14]. In addition, MetS also has an effect on AF outcome and recurrence risk catheter ablation [26, 27]. Our analysis showed a significant different result for the effect of triglycerides and AF risk as compared to other studies. In a prospective study, researchers found a higher risk of AF with elevated triglyceride levels

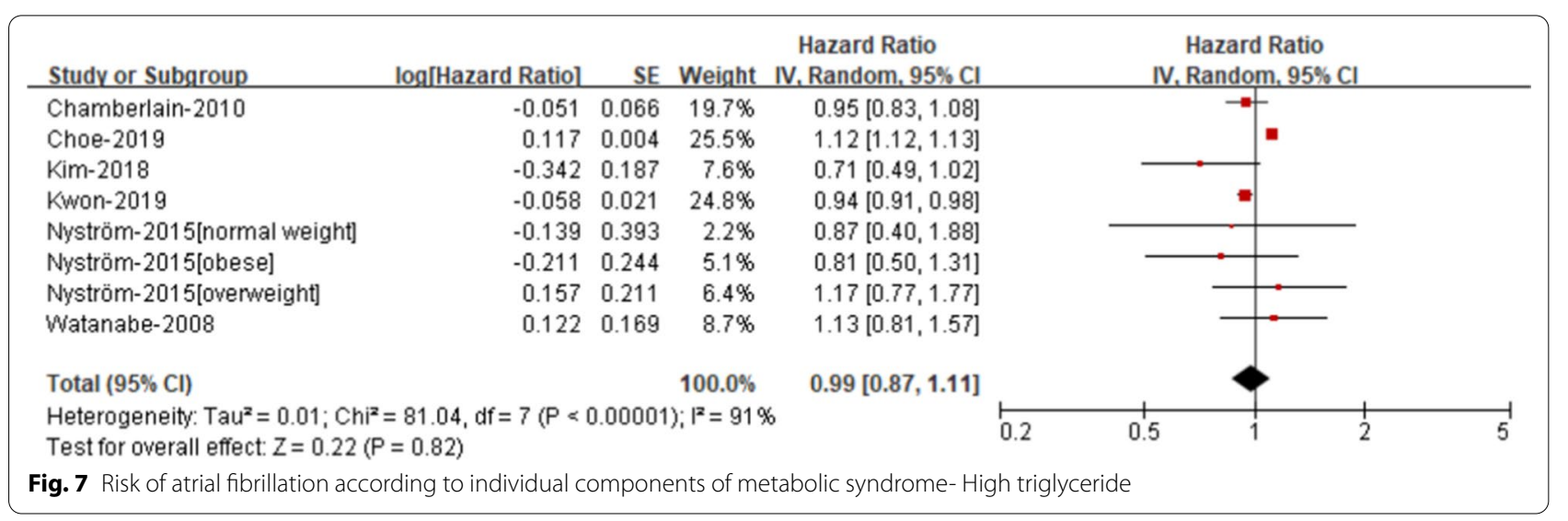


[28]. This contradictory result may be related to the age of the population included in various studies. Research found that after 70 years of age, triglyceride levels will decline, and the prevalence of AF continues to increase with age [29]. Other possible reason could be the effect of advancing age with reduced circulating TSH levels and triglyceride levels $[30,31]$. In epidemiological studies, this phenomenon may offset the effect of high triglyceride on the incidence of AF. Therefore, when analyzing the effect of high triglyceride on AF, it is necessary to group by age. Studies included in our analysis did not have specific age data thus limiting further interpretation of age and triglyceride effect. Therefore, we have concluded that high triglyceride will not affect AF.

\section{Implications and further research}

Our study results show Mets and its components have significant influence on occurrence of AF, and the control of MetS and its components may have an effective effect on reducing the prevalence of $\mathrm{AF}$.

Many studies have revealed the mechanism by which MetS increases AF risk. the possible cause of AF in MetS is the structural, functional and electrical changes of the left atrium. MetS causes increased inflammation and oxidative stress, which may lead to vascular dysfunction and makes MetS patients more prone to atrial remodeling $[32,33]$.

Among the components of MetS, hypertension and diabetes are two strong independent factors of AF [22, 23]. Experiments in a rat hypertension model show that hypertension can rapidly induce left atrium hypertrophy, fibrosis and inflammation, as well as electrophysiological changes, including shortened atrial wavelength and changes in $\mathrm{Ca} 2+$ current density [34]. These changes will increase the risk of AF. Insulin resistance leads to increased levels of $\mathrm{C}$-reactive protein in the myocardium, which can induce myocardial fibrosis and diastolic dysfunction [33] as well as atrial dilation [35]. In addition, diabetes may induce autonomic nervous system dysfunction, thereby promoting the occurrence of AF [36]. Similarly, abdominal obesity is also associated with the increase the risk of AF [24]. Obesity not only directly causes MetS, but also increases the possibility of developing other MetS components [37]. Like hypertension and diabetes, obesity also promotes oxidative stress, inflammation, and myocardial fibrosis, which induces AF [33]. In addition, obesity is also closely related to obstructive sleep apnea which is associated with the prevalence of AF [37]. However, the mechanism of the effect of blood lipids on AF is still unclear. Researchers thought that this may be related to inflammation and oxidative stress, because the anti-inflammatory and antioxidant properties of HDL particles [38] can inhibit AF [33, 39].

\section{Strengths and limitations of study}

This is the first meta-analysis on the relationship between the risk of AF and MetS as well as its components. But due to the limited number of studies, we need to acknowledge several limitations. Firstly of all, the research population of the three included studies is Korean, and in the meta-analysis, their total weight is more than 50\%, especially in the analyses of abdominal obesity and elevated fasting glucose, which may be an important reason for bias. In addition, because MetS is completely different in Asian and Caucasian patients, it may also lead to uncertainty in the study results. Secondly, use of different definitions of Mets could have increased the heterogeneity seen. But if we only use studies with the same MetS definition, there may not be enough data for analysis. Unfortunately, we failed to explore the roots of heterogeneity. Finally, due to the nature of observational data included in this met-analysis, potential confounders cannot be ruled out, which may alter the final result.

\section{Conclusions}

Our present meta-analysis suggested that MetS, as well as its components including abdominal obesity, elevated blood pressure, elevated fasting glucose and low HDL cholesterol were associated with an increase risk of AF.

\section{Supplementary Information}

The online version contains supplementary material available at https://doi. org/10.1186/s12872-021-01858-1.

Additioanl file 1. The criteria of metabolic syndrome used in the included studies and the search strategies of this meta-analysis.

\begin{abstract}
Abbreviations
AF: atrial fibrillation; BMI: Body Mass Index; HDL: high density cholesterol; MetS: metabolic syndrome; NCEP-ATPIII: National Cholesterol Education Program-Third Adult Treatment Panel; RR: risk ratio; WC: waist circumference; AHA/NHLBI: American Heart Association and National Heart, Lung, and Blood Institute; Cl: confidence interval; HR: hazard ratio; MOOSE: Meta-Analysis of Observational Studies in Epidemiology; NOS: Newcastle-Ottawa scale; SE: standard error.
\end{abstract}

\section{Authors' contributions}

$Y Z$ and $Z X$ analyzed and interpreted the metabolic syndrome and its individual components with risk of atrial fibrillation, and is the major contributor in writing the manuscript. $J \mathrm{~L}, C C$ and WC searched and proofread the included literature as required. YD checked the analysis results of this article. $C L$ and $R X$ guided the analysis and writing of this article. All authors read and approved the final manuscript.

\section{Funding}

This research was supported by Science and Technology Program Foundation of Guangzhou (No. 201610010125), Science and Technology Program Foundation of Guangdong (No. 2017A020215156), Guangdong Natural Science

Foundation (Nos. 2016A030310180). The funding bodies played no role in the 
design of the study and collection, analysis, and interpretation of data and in writing the manuscript.

\section{Availability of data and materials}

The dataset used and analyzed in the current study can be obtained from Pubmed upon reasonable request. The datasets used and/or analysed during the current study available from the corresponding author of the included researches on reasonable request.

\section{Ethics approval and consent to participate}

Not applicable for that section.

\section{Competing interests}

The authors declare that they have no conflict of interest.

\section{Author details}

${ }^{1}$ Department of Otorhinolaryngology-Head and Neck Surgery, The First Affiliated Hospital of Sun Yat-Sen University, Guangzhou, China. ${ }^{2}$ Department of Cardiology, The First Affiliated Hospital of Sun Yat-Sen University, Guangzhou 510080, China. ${ }^{3}$ NHC Key Laboratory of Assisted Circulation (Sun Yat-Sen University), Guangzhou 510080, China. ${ }^{4}$ National-Guangdong Joint Engineering Laboratory for Diagnosis and Treatment of Vascular Diseases, Guangzhou, China.

\section{Received: 8 October 2020 Accepted: 6 January 2021}

Published online: 15 February 2021

\section{References}

1. Roth GA, Johnson C, Abajobir A, Abd-Allah F, Abera SF, Abyu G, et al. Global, regional, and national burden of cardiovascular diseases for 10 causes, 1990 to 2015. J Am Coll Cardiol. 2017;70(1):1-25.

2. Rahman F, Kwan GF, Benjamin EJ. Global epidemiology of atrial fibrillation. Nat Rev Cardiol. 2014;11(11):639-54.

3. Hart RG, Benavente O, McBride R, Pearce LA. Antithrombotic therapy to prevent stroke in patients with atrial fibrillation: a meta-analysis. Ann Intern Med. 1999;131(7):492-501.

4. Benjamin EJ, Wolf PA, D'Agostino RB, Silbershatz H, Kannel WB, Levy D. Impact of atrial fibrillation on the risk of death: the Framingham Heart Study. Circulation. 1998;98(10):946-52.

5. Alberti KGMM, Eckel RH, Grundy SM, Zimmet PZ, Cleeman Jl, Donato KA et al. Harmonizing the metabolic syndrome: a joint interim statement of the International Diabetes Federation Task Force on Epidemiology and Prevention; National Heart, Lung, and Blood Institute; American Heart Association; World Heart Federation; International Atherosclerosis Society; and International Association for the Study of Obesity. Circulation. 2009;120(16):1640-5.

6. Cuspidi C, Sala C, Zanchetti A. Metabolic syndrome and target organ damage: role of blood pressure. Expert Rev Cardiovasc Ther. 2008;6(5):731-43.

7. Ford ES, Giles WH, Dietz WH. Prevalence of the metabolic syndrome among US adults: findings from the third National Health and Nutrition Examination Survey. JAMA. 2002;287(3):356-9.

8. Watanabe H, Tanabe N, Watanabe T, Darbar D, Roden DM, Sasaki S, et al. Metabolic syndrome and risk of development of atrial fibrillation: the Niigata preventive medicine study. Circulation. 2008;117(10):1255-60.

9. Choe WS, Choi EK, Han KD, Lee EJ, Lee SR, Cha MJ, et al. Association of metabolic syndrome and chronic kidney disease with atrial fibrillation: a nationwide population-based study in Korea. Diabetes Res Clin Pract. 2019;148:14-22.

10. Kim YG, Choi KJ, Han S, Hwang KW, Kwon CH, Park GM, et al. Metabolic syndrome and the risk of new-onset atrial fibrillation in middle-aged East Asian Men. Circ J. 2018;82(7):1763-9.

11. Kwon CH, Kim H, Kim SH, Kim BS, Kim HJ, Kim DK, et al. The impact of metabolic syndrome on the incidence of atrial fibrillation: A Nationwide Longitudinal Cohort Study in South Korea. J Clin Med. 2019;8(8).

12. Chamberlain AM, Agarwal SK, Ambrose M, Folsom AR, Soliman EZ, Alonso A. Metabolic syndrome and incidence of atrial fibrillation among blacks and whites in the Atherosclerosis Risk in Communities (ARIC) Study. Am Heart J. 2010;159(5):850-6.
13. Nystrom PK, Carlsson AC, Leander K, de Faire U, Hellenius ML, Gigante B. Obesity, metabolic syndrome and risk of atrial fibrillation: a Swedish, prospective cohort study. PLoS ONE. 2015;10(5):e0127111.

14. Vyssoulis G, Karpanou E, Adamopoulos D, Kyvelou S, Tzamou V, Michaelidis A, et al. Metabolic syndrome and atrial fibrillation in patients with essential hypertension. Nutr Metab Cardiovasc Dis. 2013;23(2):109-14.

15. Stroup DF, Berlin JA, Morton SC, Olkin I, Williamson GD, Rennie D, et al. Meta-analysis of observational studies in epidemiology: a proposal for reporting. Meta-analysis Of Observational Studies in Epidemiology (MOOSE) group. JAMA. 2000;283(15):2008-12.

16. Executive Summary of the Third Report of the National Cholesterol Education Program (NCEP) Expert Panel on Detection, Evaluation, and Treatment of High Blood Cholesterol in Adults (Adult Treatment Panel III). JAMA, 2001;285(19), 2486-2497.

17. Alberti KGMM, Zimmet P, Shaw J. The metabolic syndrome-a new worldwide definition. Lancet. 2005;366(9491):1059-62.

18. Grundy SM, Cleeman JI, Daniels SR, Donato KA, Eckel RH, Franklin BA, et al. Diagnosis and management of the metabolic syndrome: an American Heart Association/National Heart, Lung, and Blood Institute Scientific Statement. Circulation. 2005:112(17):2735-52.

19. Zhou Y, Ma JY, Zhu WG. Efficacy and safety of direct oral anticoagulants versus warfarin in patients with atrial fibrillation across BMl categories: a systematic review and meta-analysis. Am J Cardiovasc Drugs. 2020;20(1):51-60.

20. Zhou Y, Wang C, Shi K, Yin X. Relation of metabolic syndrome and its components with risk of diabetic retinopathy: a meta-analysis of observational studies. Medicine. 2018;97(38):e12433-e12433.

21. Kontopantelis E, Reeves D. Performance of statistical methods for meta-analysis when true study effects are non-normally distributed: a simulation study. Stat Methods Med Res. 2012;21(4):409-26.

22. Huxley RR, Filion KB, Konety S, Alonso A. Meta-analysis of cohort and case-control studies of type 2 diabetes mellitus and risk of atrial fibrillation. Am J Cardiol. 2011;108(1):56-62.

23. Verdecchia P, Angeli F, Reboldi G. Hypertension and atrial fibrillation: doubts and certainties from basic and clinical studies. Circ Res. 2018;122(2):352-68.

24. Aune D, Sen A, Schlesinger S, Norat T, Janszky I, Romundstad P, et al. Body mass index, abdominal fatness, fat mass and the risk of atrial fibrillation: a systematic review and dose-response meta-analysis of prospective studies. Eur J Epidemiol. 2017:32(3):181-92.

25. Umetani K, Kodama Y, Nakamura T, Mende A, Kitta Y, Kawabata K, et al. High prevalence of paroxysmal atrial fibrillation and/or atrial flutter in metabolic syndrome. Circ J. 2007;71(2):252-5.

26. Lin KJ, Cho SI, Tiwari N, Bergman M, Kizer JR, Palma EC, et al. Impact of metabolic syndrome on the risk of atrial fibrillation recurrence after catheter ablation: systematic review and meta-analysis. J Interv Card Electrophysiol. 2014;39(3):211-23.

27. Wojcik M, Berkowitsch A, Kuniss M, Zaltsberg S, Pitschner H, Hamm CW et al. Outcomes of atrial fibrillation ablation in patients with metabolic syndrome. J Am Coll Cardiol. 2013;109-10.

28. Alonso A, Yin X, Roetker NS, Magnani JW, Kronmal RA, Ellinor PT, et al. Blood lipids and the incidence of atrial fibrillation: the Multi-Ethnic Study of Atherosclerosis and the Framingham Heart Study. J Am Heart Assoc. 2014;3(5):e001211.

29. Miller M, Stone NJ, Ballantyne C, Bittner V, Criqui MH, Ginsberg $\mathrm{HN}$, et al. Triglycerides and cardiovascular disease: a scientific statement from the American Heart Association. Circulation. 2011;123(20):2292-333.

30. Asvold BO, Vatten LJ, Nilsen TIL, Bjøro T. The association between TSH within the reference range and serum lipid concentrations in a population-based study. The HUNT Study Eur J Endocrinol. 2007;156(2):181-6.

31. Mazzoccoli G, Pazienza V, Piepoli A, Muscarella LA, Inglese M, De Cata A, et al. Hypothalamus-hypophysis-thyroid axis function in healthy aging. J Biol Regul Homeost Agents. 2010;24(4):433-9.

32. Zanoli L, Di Pino A, Terranova V, Di Marca S, Pisano M, Di Quattro R, et al. Inflammation and ventricular-vascular coupling in hypertensive patients with metabolic syndrome. Nutr Metab Cardiovasc Dis. 2018;28(12):1222-9.

33. Guo Y, Lip GYH, Apostolakis S. Inflammation in atrial fibrillation. J Am Coll Cardiol. 2012;60(22):2263-70. 
34. Choisy SCM, Arberry LA, Hancox JC, James AF. Increased susceptibility to atrial tachyarrhythmia in spontaneously hypertensive rat hearts. Hypertension. 2007:49(3):498-505.

35. Kadappu KK, Boyd A, Eshoo S, Haluska B, Yeo AET, MarwickTH, et al. Changes in left atrial volume in diabetes mellitus: more than diastolic dysfunction? Eur Heart J Cardiovasc Imaging. 2012;13(12):1016-23.

36. Otake H, Suzuki H, Honda T, Maruyama Y. Influences of autonomic nervous system on atrial arrhythmogenic substrates and the incidence of atrial fibrillation in diabetic heart. Int Heart J. 2009:50(5):627-41.

37. Goudis CA, Korantzopoulos P, Ntalas IV, Kallergis EM, Ketikoglou DG.

Obesity and atrial fibrillation: A comprehensive review of the pathophysiological mechanisms and links. J Cardiol. 2015;66(5):361-9.
38. Rye K, Barter PJ. Cardioprotective functions of HDLs. J Lipid Res. 2014;55(2):168-79.

39. Yang K, Dudley SCJ. Oxidative stress and atrial fibrillation: finding a missing piece to the puzzle. Circulation. 2013;128(16):1724-6.

\section{Publisher's Note}

Springer Nature remains neutral with regard to jurisdictional claims in published maps and institutional affiliations.
Ready to submit your research? Choose BMC and benefit from:

- fast, convenient online submission

- thorough peer review by experienced researchers in your field

- rapid publication on acceptance

- support for research data, including large and complex data types

- gold Open Access which fosters wider collaboration and increased citations

- maximum visibility for your research: over $100 \mathrm{M}$ website views per year

At BMC, research is always in progress.

Learn more biomedcentral.com/submissions 